\title{
Fetus in Fetu: A Case Report and Review of Literature
}

Authors: Wobenjo A ${ }^{\mathbf{1}}$, MBChB., Osawa $\mathbf{F}^{\mathbf{2}}$, MBChB, MMed (Surgery), Kenyatta National Hospital. Affliation: 1. Resident Dept of Surgery, University of Nairobi, 2. Senior Registrar, Dept. Of Pediatric surgery Correspondence: Adili Wobenjo. Po. Box 286-00202 KNH, Nairobi. E-mail: adilihw@yahoo.com

\section{Summary}

Fetus-in-fetu is a rare congenital malformation in which a vertebra fetus is enclosed within the abdomen of a normally developing fetus. The preoperative diagnosis is challenging. Less than 200 cases are reported in English literature, five in Africa. Multiple fetuses-in-fetu are less documented. We report a three month old infant who presented with an abdominal mass and constipation and taken to theatre with a preoperative diagnosis of a teratoma. At operation, the mass was a case of twin fetuses in fetu with blood supply from the aorta and the left renal artery. Total excision of the mass with special attention to its blood supply was therapeutic.

We emphasize the necessity for suspicion of fetus in fetu when a well-defined encapsulated cystic mass with calcified solid components is detected by an abdominal CT scan in a child less than 2 years of age.

\section{Introduction}

A large solid abdominal tumor in a pediatric patient can be a big challenge for clinician because of many differential diagnoses, some of these rare (1). Fetus in fetu is a rare cause and represents an unequal division of totipotential cells of a blastocyst where the result is the inclusion of a small cellular mass in the more mature embryo. This is a form of monozygotic diamniotic twin pregnancy where the parasitic twin installs and grows in the body of its partner. This condition has some similarities with the retroperitoneal teratoma, but is differentiated by its fetiform aspect and the metameric segmentation of its spinal axis (2).The term fetus in fetu was coined by Meckel (3) in the 18th century who defined it as a parasitic twin found within the abdomen of its sibling. To date, less than 200 cases have been reported in English literature (4). Commonly, fetus in fetu is described without a well defined vascular pedicle (5). We report a case of twin fetus in fetu that was connected by two vessels to its host.

\section{Case Report}

A 3 month old infant was referred to Kenyatta National Hospital with an abdominal mass. The parents had noticed a progressive left sided abdominal swelling for a month and associated constipation for 2 weeks. There was a family history of twinning on the maternal side. The infant had one sibling who was alive and well. The pregnancy was uneventful and the patient was born at full term by an uncomplicated vaginal delivery. The mother started attending antenatal clinic at 6 months and no obstetric ultrasound was done.

On examination, the infant was in good general condition and not pale. The abdomen was distended with a large palpable non tender mass in the left upper and lower quadrants. The spleen and the liver were not palpable. The baby had a normal anal orifice and female external genitalia. The respiratory and cardiovascular systems were normal.

A full blood count, urea, electrolytes, creatinine and coagulation screens were normal.

A CT scan of the abdomen showed a large heterogeneous mass measuring 122.3 by $122.1 \mathrm{~mm}$ arising from the pelvis and displacing the bowel loops to the periphery. The mass had a cystic component with septation which showed post contrast rim enhancement (fig 1 and 2). A calcific density was seen within the mass (fig 1). The left kidney was markedly hydronephrotic with minimal lateral deviation, suggesting the retroperitoneal location of this abdominal mass.

A laparatomy was performed through a transverse supraumbilical incision and a large encapsulated mass with cystic and solid areas occupying approximately two thirds of the peritoneal cavity was found. It was perfused by direct branches from the aorta and the left renal artery. After its covering membranes were opened, two 


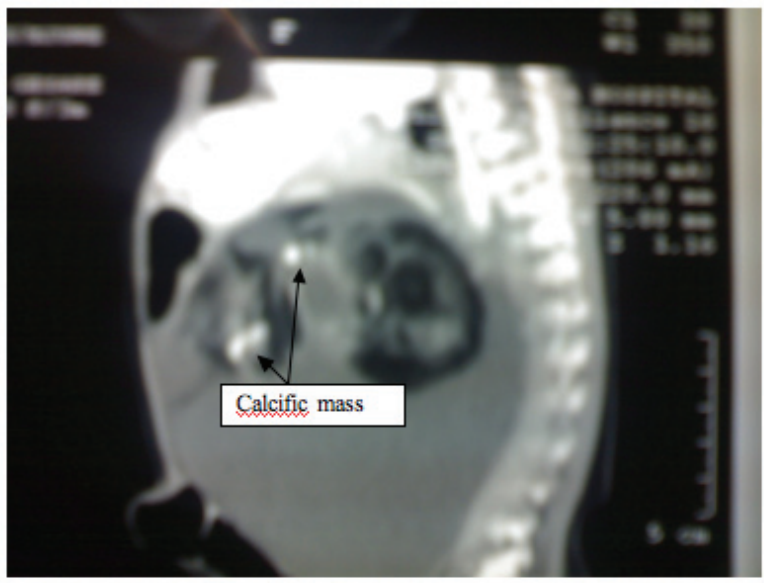

Figure 1: Saggital abdominal CT scan demonstrating the two fetuses in the upper peritoneum with surrounding cyst. Arrow shows the calcific density.

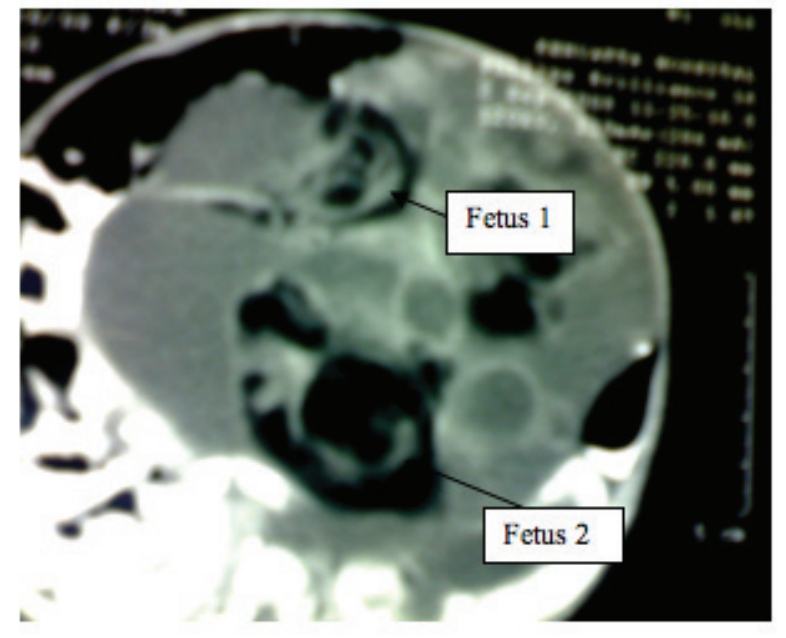

Figure 2: Axial abdominal CT scan demonstrating the two fetuses

quarters of reported symptomatic cases have presented in infancy (5) with the oldest reported case in a 47 years old adult (8). Reported cases weighed between 1.2grams and 2000 grams (8) depending on adequacy of perfusion. The mass in the present case weighed 990 grams. The pathogenesis of fetus in fetu is not fully understood. According to Willis, fetus in fetu is an aberration of monozygotic diamniotic twinning in which unequal division of the totipotent inner cell mass of the developing blastocyst leads to the inclusion of a smaller cell mass within a maturing sister embryo $(9,10)$. The arrangement of limb structures around a vertebral axis is a step too far in embryological development to correspond to a teratoma, the alternative theory (11). Moreover, molecular analysis using genetic markers of chromosomes shows genetic identity between the host infant and the fetiform mass supporting the diagnosis and facilitating the distinction from malignant teratoma (12).

Proponents of the teratoma theory consider that pathological findings are explained by development of an original germinal cell up to a well-differentiated stage called fetiform teratoma. They believe that the fetus in fetu should be considered as a potentially malignant lesion, malignant teratomas having been found in certain bearers of this anomaly (13). Moreover, the monozygotic twin theory does not sufficiently explain the occurrence of multiple fetuses in fetu and its association with teratomas. Further, a recent study showed differential 


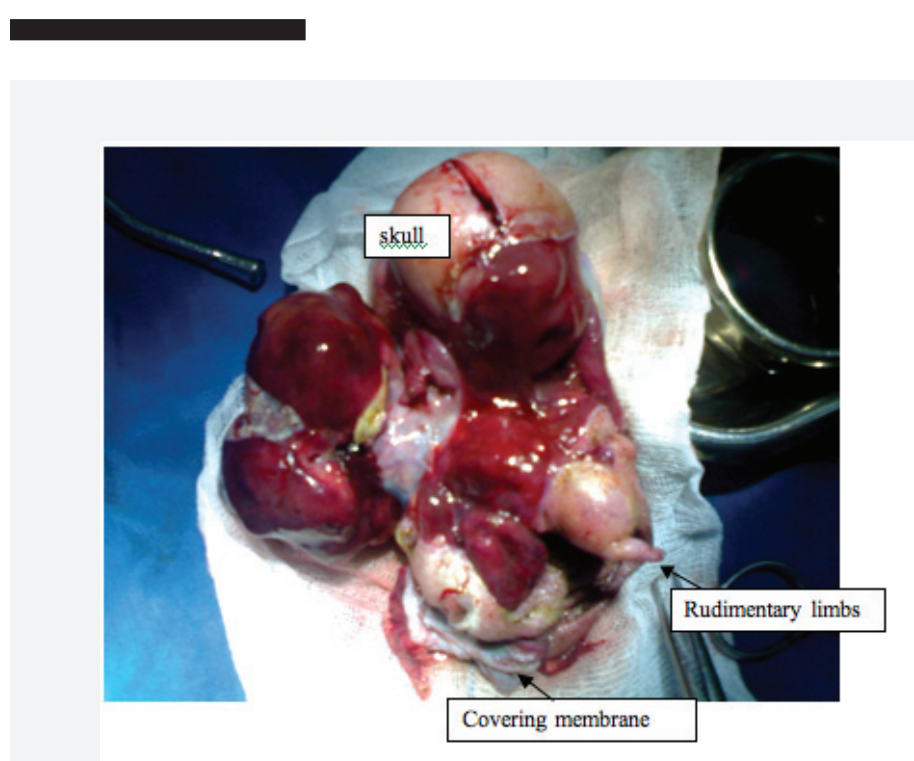

Figure 3: Photography of the rudimentary fetuses after total excision. Arrows show a well formed skull limbs and covering membrane

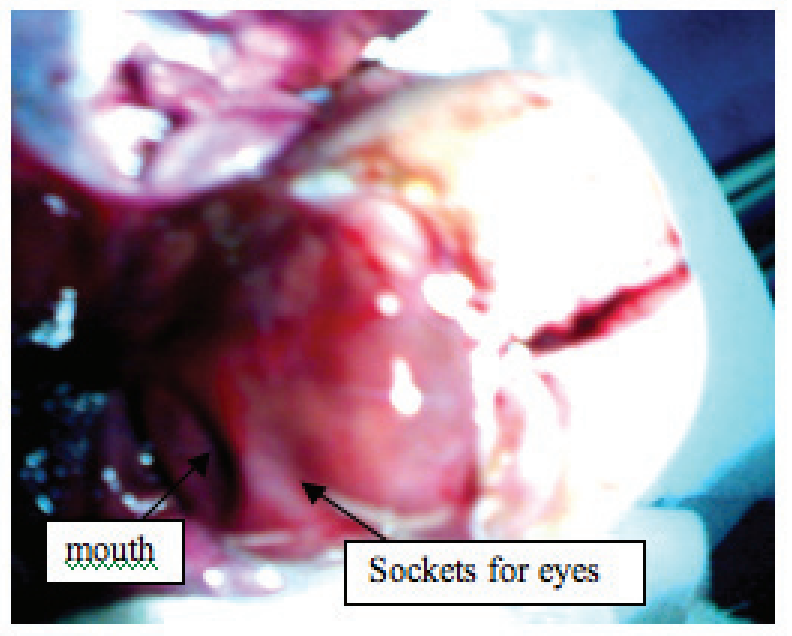

Figure 4: Photography of the fetal head demonstrating sockets for the eyes and mouth methylation patterns within the human IGF2-H19 locus between the host infant and the fetiform mass (14). Spencer (15) presents convincing data that FIF and many teratomas are aberrations of monozygotic twinning. The well-reasoned synthesis of the embryologic evidence by Spencer points to a spectrum of anomalies ranging from conjoined twins to malformed external parasitic and acardiac twins to FIF and so-called "fetiform" teratomas to well-differentiated teratomas. Depending on the degree of malformation and timing of the embryologic insult, interruptions of monozygotic twinning can lead to any of these observed phenomena. Fetus in fetu is thought to occur at an early stage of development, before ventral fusion of the lateral body walls. FIF and teratomas could thus represent a continuum. Supporting this hypothesis are the observations that FIF and teratomas are increased in families with a history of twinning; FIF may contain multiple fetuses; FIF and teratomas can coexist (13) and FIF and teratomas are found in locations that are involved embryologically in conjoined twinning (15).

Majority of the cases, including the present report, are diagnosed at surgery. Only in $16.7 \%$ of these cases was it possible to show a preoperative diagnosis of FIF, differential diagnosis usually being teratoma and meconium pseudocyst (12). The lesions show variable gross and radiologic features, microscopic characteristics and anatomic locations. In the patient in the present report, one of the twin fetuses in fetu had a well developed skull with distinct facial features namely a primitive mouth eyes and nose. The distinction between FIF and teratoma has implications for both prognosis and management. Malignant degeneration is very rare in a fetus in fetus (16), whereas retroperitoneal teratomas are characterized by progressive growth and have definite malignancy potential with metastases to lungs, liver and vertebrae. Definitive vascular connection to the host is rarely described (9) and the absence of an independent circulatory system could account for the subsequent fetal retardation. In our case the fetus in fetu derived its blood supply directly from the aorta and the left renal artery. In the present case, the left kidney derived its blood supply through the mass and not directly from the left renal artery and was hydronephrotic due to obstruction of its ureter by the mass. This informed its excision.

At surgery we completely excised the mass with its surrounding membranes. This is necessary to ensure definitive cure, prevent any future pressure effects, adhesions of the sac to surrounding structures as it becomes fibrous with time and to obviate dangers of infection, infarction or hemorrhage and malignant transformation $(5,16)$. Although the prognosis is favorable, the presence of immature elements mandates close clinical, radiological and serological (AFP, $\beta$ HCG) follow up (16).

Spencer (15) has suggested that an FIF must have one or more of the following conditions: (i) be enclosed within 
a distinct sac; (ii) be partially or completely covered by normal skin; (iii) have grossly recognizable anatomic parts; (iv) be attached to the host by only a few relatively large blood vessels; and (v) either be located immediately adjacent to one of the sites of attachment of conjoined twins or be associated with the neural tube or the gastrointestinal system. Our case fulfilled the five conditions: was enclosed within a sac, was partially covered by normal skin, had grossly recognizable anatomic parts, attached to the host by blood vessels- branches from the aorta and the left renal artery and was located in the retroperitoneal region (site adjacent to site of attachment of conjoined twins)

\section{Conclusion}

Fetus in fetu is a rare entity. We emphasize the necessity for the suspicion of fetus in fetu when a well defined encapsulated cystic mass with calcified solid components is detected by an abdominal CT scan for a child less than 2 years of age.

\section{References}

1. Tofigh, A.M, Kavyani, A., Abdollahi, S.M, et al. Fetus in fetu: Report of a case and literature review Int. J. of Surg. 2008; 6:e94-e96

2. Hoeffel CC, Nguyen KQ, Phan HT, et al . Fetus in fetu: A case report and literature review. Pediatrics 2000; 105:1335-44.

3. Meckel J. Intraabdominal fetus in fetu. J Pathol Bacteriol, 1956; 72:62

4. Abdur-Rahman LO, Abdul-Kadir AY, Rahman AG. Fetus -in -fetu in a 6-month-old. Afr. J. Paed. Surg 2008;5:96-8
5. Higgins KR, Coley BD. Fetus in fetu and feta form teratoma in 2 neonates: an embryologic spectrum? J Ultrasound Med 2006;25(2): 259-263

6. Bhat BV, Madhu SR, Nalini N, et al. Twin Fetus in Fetu. Indian ] Pediatr 1998; 65 : 622-626

7. Dagradi AD,Manglante GL,Serio GF, et al. Fetus in fetu removal in a 47 year old man. Surgery 1992:112

8. Mohta A, Shrivastava UK, Sodhi P, Upreti L. Fetus-in-fetu Pediatr Surg Int 2003;19: 499-500

9. Gonzalez-Crussi F. Extragonadal teratomas. Atlas of tumor pathology. 2nd ser., fasc. 18. Armed forces institute of Pathology. Washington DC. 1982

10. Willis RA. The structure of teratomata. J Pathol Bacteriol $1935 ; 40: 1-36$.

11. Brand A, Alves MC, Saraiva C, et al. Fetus in fetu-diagnostic criteria and differential diagnosis-a case report and literature review. J. of Paed. Surg. 2004;39(4): 616-618

12. Hanquinet $S$, Damry N, Heimann $P$, et al. Association of a fetus in fetu and two teratomas: US and MRI. Pediatr Radiol 1997; 27: 336-338

13. Miura S, Miura K, Yamamoto T. Origin and mechanisms of formation of fetus-in-fetu: two cases with genotype and methylation analyses. Am J Med Genet A 2006; 140(16): 1737-1743.

14. Spencer R. Parasitic conjoined twins: external, internal (fetuses in fetu and teratomas), and detached (acardiacs). Clin Anat 2000; 14(6): 428-444.

15. Hopkins KL, Dickson PK, Ball TI, et al. Fetus in fetu with malignant recurrence. Journal Paed Surg Intl 1997:32:1476-9

16. Patankar T, Fatterpekar G M,Prasad S, et al, Fetus in fetu ;CT appearance report of two cases. Radiology 2000;214:735-7 